\title{
فاعلية الستفدم تقنية الواقع المعزز علي تنمية مهارة تصميم الأزياء الرقمي
}

أ.د/ عمرو جمال الدين حسونة

بقسم الملابس الجاهزة كلية الفنون النطبيقيةجامعة حلوان

$$
\text { أ.د/ محمد البدري عبدالكريم }
$$

أستاذ الآلات بقسم الملابس الجاهزه كلية الفنون التطبيقية - جامعة حلوان

\section{م/سارة محمد سعيد علي}

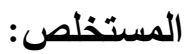

هدف البحث الحالي الى التعرف على فاعلية استخدم تقنية الواقع المعزز علي تتمية مهارة

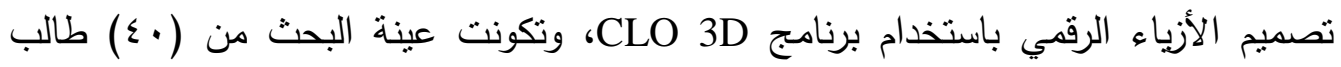

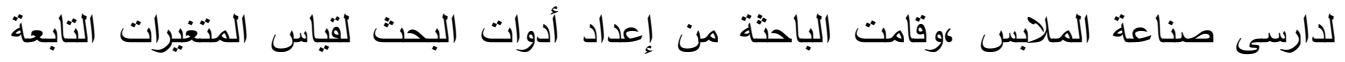
لاختبار تتمية مهارة تصميم الأزياء الرقمي باستخدام تقنية الواقع المعزز وللتحقق من صحة الإنة

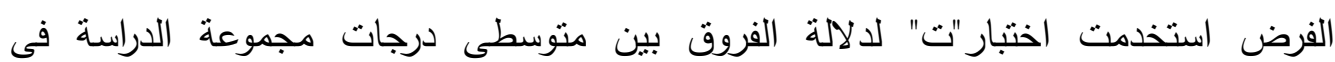

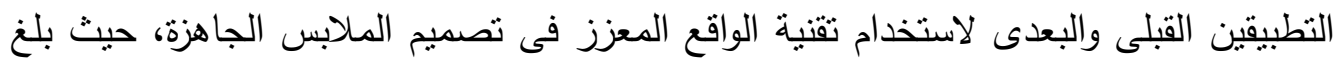

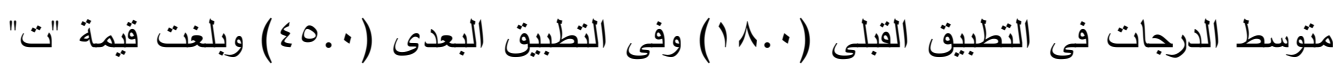
(YV.OV)

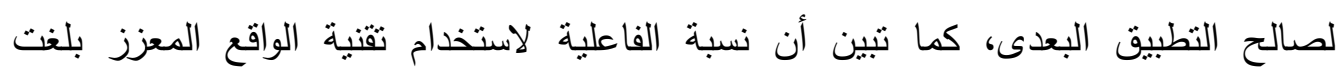

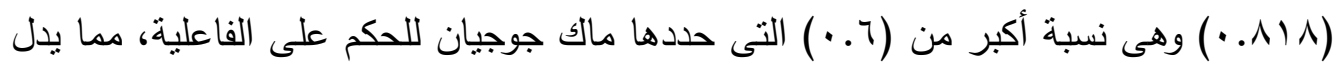
على فاعلية استخدام تقنية الواقع المعزز فى تتمية مهارة تصميم الملابس الجاهزة الرقمي. الكلمات المفتاحية: الواقع المعزز، تصميم الأزياء الرقمي 


\section{Abstract:}

The aim of the current research is to identify the effect of using augmented reality technology on developing the skill of digital fashion design using a program CLO 3D, the research sample consisted of (40) students studying the clothing industry, and the researcher prepared the research tools to measure the variables of the digital fashion design skill development test using augmented reality technology, and to verify the validity of the hypothesis, the "T" test was used to indicate the differences between the mean scores of the study group. In the pre and post applications, the use of augmented reality technology in designing ready-made clothes, where the average score in the pre-application was (18.0) and in the post application (45.0), the value of " $T$ " was (27.57) and the level of significance (0.001), which indicates a statistically significant difference. Between the two applications in favor of the post application, it was also found that the effectiveness rate of using augmented reality technology was $(0.818)$, which is greater than (0.6) that was determined by Mac Gojian to judge the effectiveness, which indicates the effectiveness of using augmented reality technology in developing the skill of digital ready-to-wear design. 


\section{مقدمة البحث:}

في عصر التكنولوجيا والانفتاح التقني والمعرفي، كان من الضروري مواكبة هذا التطور

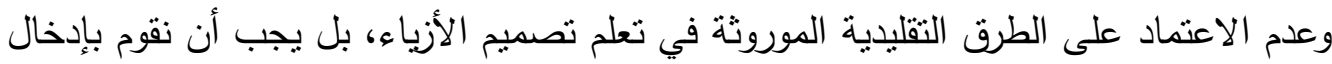

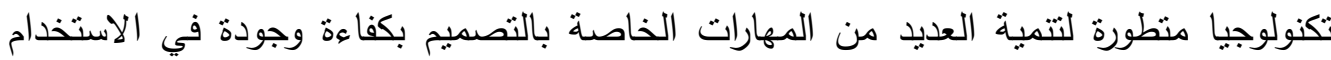

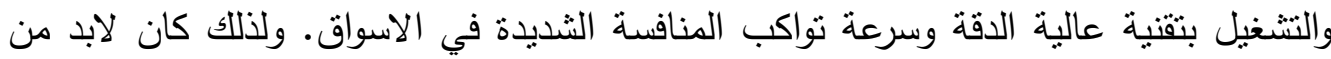
استخدام مثل تلك التكنولوجيا المتطورة على نمو الخيال الفني والعلمي وتتمية مهارات الخاصة بالتصميم.

حيث ذكر أندرسون وليروكبيس (Liarokapis\&Anderson:2010) "أن تقنية الواقع المعزز تمتاز بأنها بسيطة وفعالة وتمكن المعلم من إدخال معلوماتواته وبياناته وإيصالها بطريقة

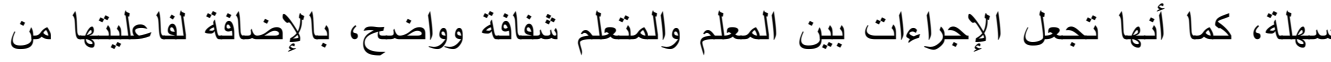

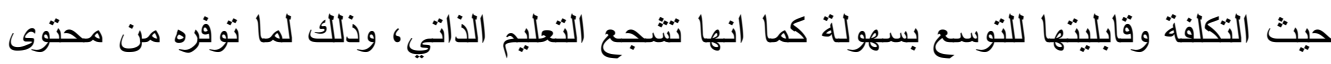
تعليمي يسهل علي الطالب الرجوع إليه في المنزل."

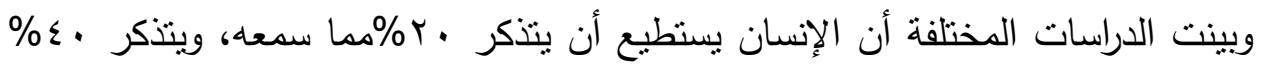

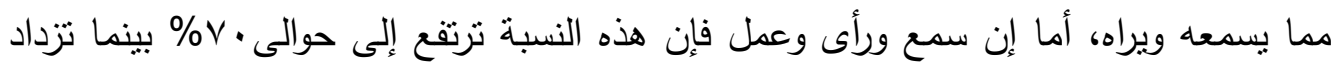

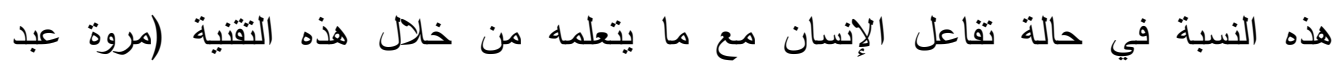

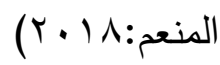

ويُعد الحاسوب ووسائل العرض التفاعلي وتقنيات الاتصال من اهم وسائل تكنولوجيا

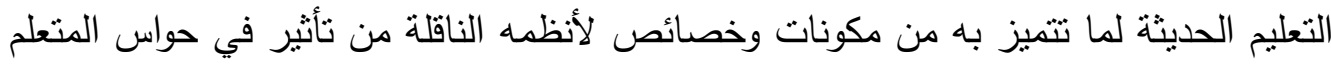

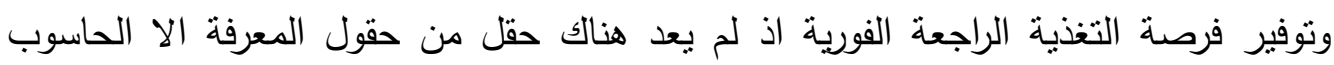

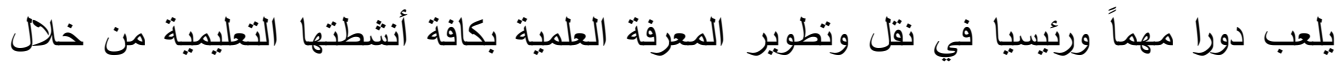

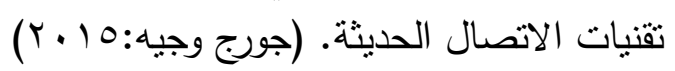

واستخدام التقنيات الحديثة كالواقع المعزز في العملية التعليمية يبعد الطالب عن الروتين

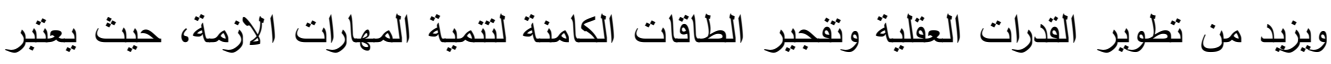

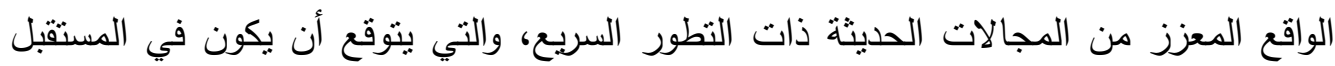

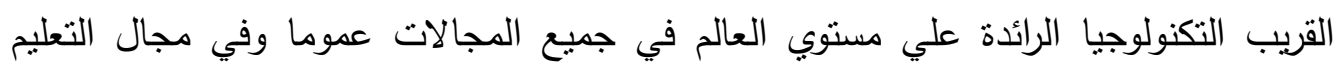

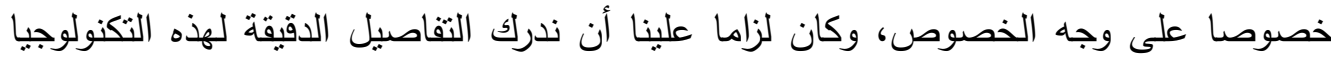

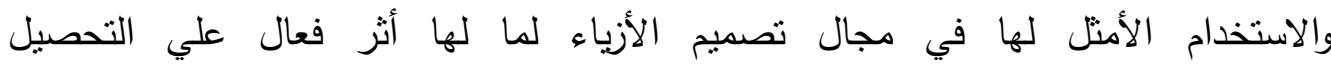

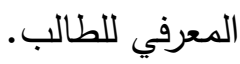


للتصدي لهذه المشكلة تحاول الدراسة الحالية الإجابة علي التساؤلات التالية:

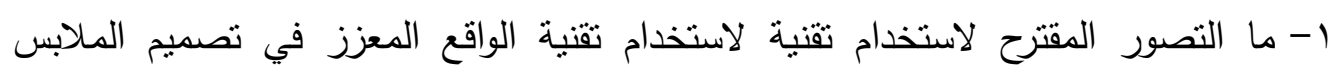
الجاهزة في ضوء (المهارات المطلوبة، سرعة، سهولة الاستخدام). r- ما فاعلية استخدم تقنية الواقع المعزز علي تتمية مهارة تصميم الأزياء الرقمي.

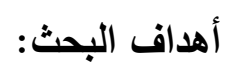
يسعي البحث الحالي الي محاولة تحقيق الأهداف الآتية:

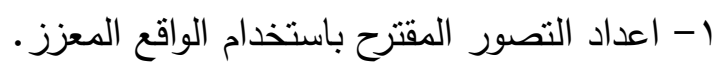
ץ- التحقق من فاعلية الواقع المعزز في تتمية مهارة تصميم الأزياء لدي الطلاب محل الدراسة. r- اكتساب المهارات الازمه للارسين لتصميم الأزياء.

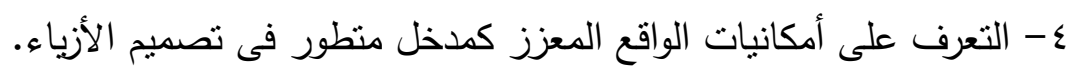
أهمية البحث:

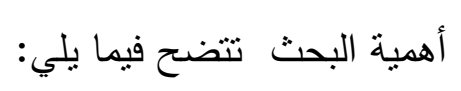

• توفير وسائل نعليمية تفاعلية تعتمد على المشاركة ومصمدة خصيصا لمقررات تصميم الأزياء.

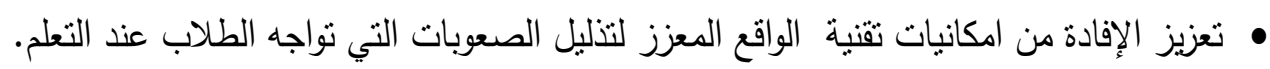

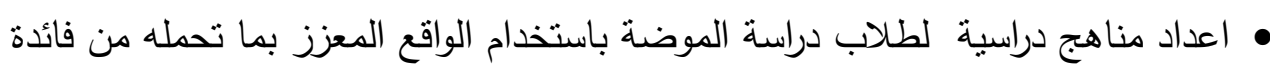
للمعلمين والمتعلمين.

• حث المتعلم علي استخدام تكنولوجيا الواقع المعزز للارتقاء بالمستوي التحصيلي للطالب .

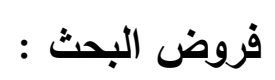
• وجود دلاله احصائية لصالح استخدام تقنية الواقع المعزز فى دراسة تصميم الأزياء.

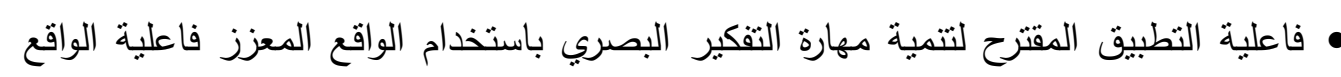
المعزز في تتمية مهارة تصميم الأزياء لدي الطلاب محل الدراسة. حدود البحث : اقتصر البحث الحالي على الحدود التالية: - حدود بشرية: متدربين حاضنة أعمال لصناعة الملابس الجاهزة. 
- - حدود مكانية: بمعهد حاضنة الأعمال جامعة حلوان. - - حدود موضوعية: مقرر تصميم أزياء.

- - حدود زمانية: تم تطبيق تجربة البحث في الفصل الدراسي الأول للعام الدراسي

$$
\begin{aligned}
& \cdot r \cdot r \cdot / r \cdot 19 \\
& \text { منهج البحث: } \\
& \text { اعتمد البحث على كلًا من :- } \\
& \text { - المنهج الوصفي. } \\
& \text { - المنهج التجريبي. } \\
& \text { مصطلحات البحث }
\end{aligned}
$$

الواقع المعزز) Augmented Reality (AR)

التقنية الناشئة التي تسمح بمزج المعلومات القادمة من العالم الحقيقي مع المعلومات الرقمية التي يتم معالجتها من قبل الكمبيوتز عن طريق واجهات الكمبيوتز المناسبة. ويستخدم

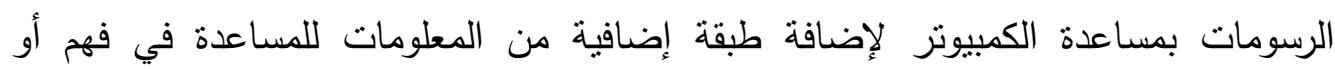
التفاعل مع العالم المادي من حوللك. (مروة إبراهيم سليمان:2018)

$$
\text { تصميم الأزياء الرقمي }
$$

يقصد بالتصـيم الرقمي للأزيـاء التصـميم بمسـاعدة الكمبيوتر Computer Aided

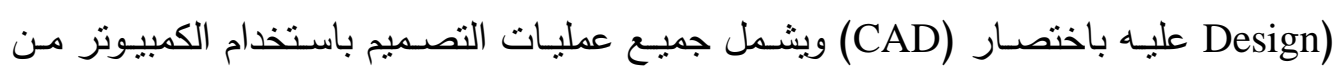
تصـميم، تطوير ، تحليـل عـرض تتظيم، معالجـات وتعـديل التصـميم؛ وكمـا هـو معلـوم فـإن

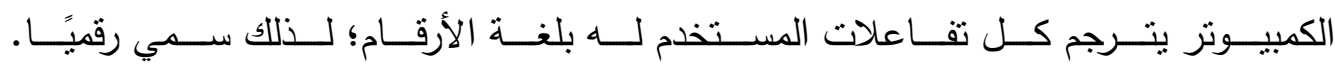

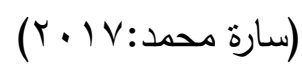


الإطار النظري والدراسات المرتبطة :

ينقسم الإطار النظري في البحث الحالي إلى محاورين اساسين اساسية هما: أولا: تقنية الواقع المعزز ثانيا: تصميم الأزياء الرقمي

\section{أولا: تقنية الواقع المعزز}

يتتاول هذا المحور الواقع المعزز من حيث تعريفة ، خصائصه ،أنواعه، استخدامه في التعليم

\section{تعريف الواقع المعزز:}

نظرًا لحداثة مفهوم الواقع المعزز فقد تعددت المصطلحات التي تثير إليه؛ ومن خلال

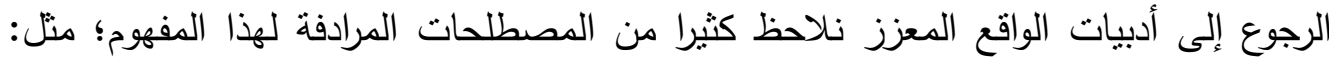
"الواقع المضاف والواقع المزيد، والواقع الموسّع؛ والواقع المحسن؛ والواقع المدمجج" والحقيقة

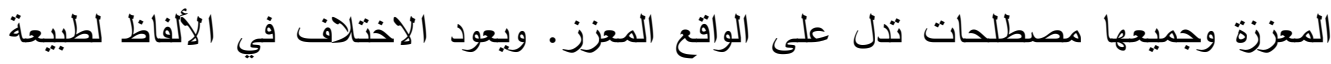
الترجمة؛ وفي هذه الدراسة نم استخدام مصطلح (الواقع المعزز) على اعتبار أنه المصطلح الأكثر استخداما في الأدبيات المترجمة إلى العربية.

وعرف بيج Beige الواقع المعزز بأنه: نظام بعتمد على رؤية العالم الحقيقي بشكل مباشر

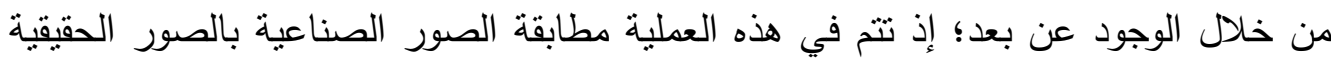
لتزويدنا بعناصر حقيقية ومعلومات إضافية ريما تكون خفية عند رؤيتها من خلاهل العين العين

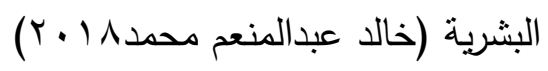

وعرف لارسن و بوغتر Bogner Larsen، الواقع المعزز بأنه: بيانات رقمية وتركيبها وتصويرها باستخدام طرق عرض رقمية للواقع الحقيقي للبيئة المحيطة بالكائن الحي؛ ومن بن باتهن

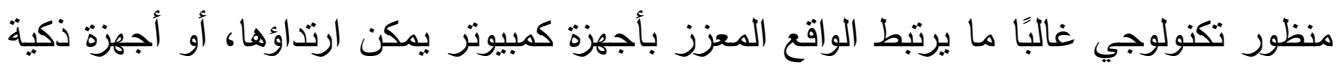

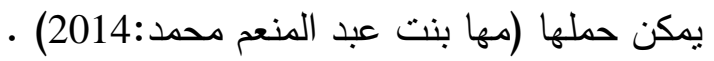
تعتمد فكرة الواقع المعزز على ربط معالم من الواقع الحقيقي بالعنصر الافتراضي المناسب لها والمخزن مسبقا في ذاكرته، أي انها تكنولوجيا تقاعلية منزامنة تدمج فيها خصائص العالم الحقيقي مع العالم الافتراضي بشكل ثنائي أو ثلاثي الابعاد، كما تعتمد أغلب البرامج داخل 
أنظمة الواقع المعزز حتى وقت قريب على تبعاً استخدام كاميرا الهاتف المحمول أو الكمبيوتر اللوحي لروية الواقع الحقيقي، ثم تحليله لما هو مطلوب من البرنامج والعمل على دمج العناصر

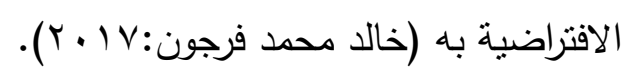

ويمكن القول بأن الواقع المعزز تعزيز الواقع الحقيقي المنواجدين فيه بأثنياء افتراضية

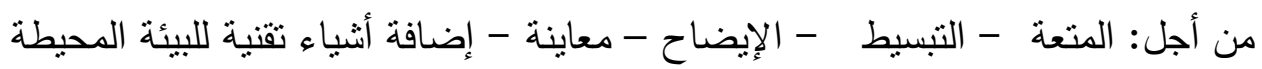

خصائص الواقع المعزز

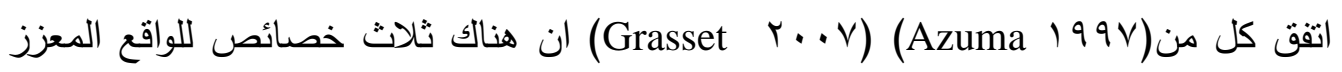

$$
\text { • • تضضح فيما يلي: توفم بالتفاعلية في وقت استخدامها . }
$$

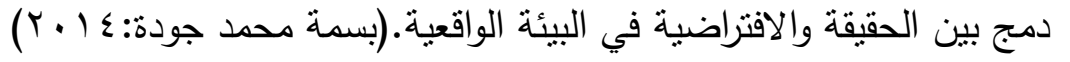

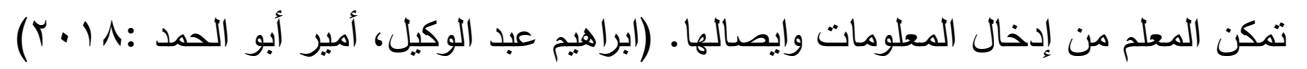

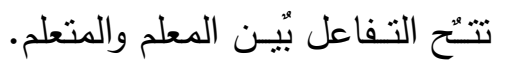

•ـــواكب التطور السرُعَ في المعرفة.

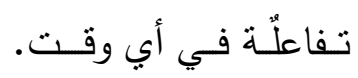

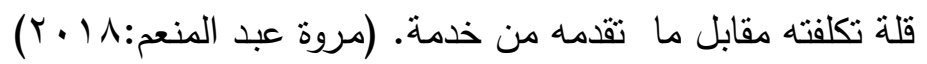

$$
\text { • توفر معلومات واضحة ودقيقة. }
$$

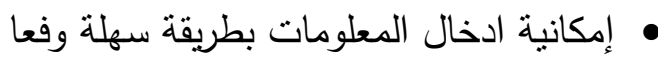
• إمكانية التفاعل بين طرفين مثل: (معلم ومتعلم). رغم بساطة الاستخدام إلا أنها تقدم معلومات قوية. جعل الإجراءات المعقدة سهلة للمستخدمين فعالة من حيث التكلفة وقابلة للتوسيع بسهولة. التعاون والمشاركة بين المواد الحقيقية 
التفاعل الفوري بين المواد ال والافتراضية عن طريق دمج البيانات الرقمية مع البيئة الواقعية من اجل تزويد الطلاب بالخبرة الحسية الفائقة والتفاعل يتم في ثلاثة صور بين المتعلم والمحتوى التعليمي؛ وبين المتعلم والوسائل التعليمية · تقاعل الطلاب بعضهم البعض وذلك لمساعدة الطلاب للتوصل لحل المشكلات عن طريق التعاون والعمل الجماعي (هناء رزق: $\cdot(r \cdot) \mathrm{V}$ تمد المتعلم والمشاهد بصور وفيديوهات مزودة بمعلومات تتدمج مع الصورة التي ينظر اليها.

تجعل العملية التعليمية أكثر تفاعلية وتواصل ونشاط. • تقنية يستخدم فيها أجهزة الهواتف الذكية والحواسيب والأيباد.

• تقنية تسمح بذاتية التعلم وتفريد التعليم ليتتاسب قدرات واستعدادات المتعلم وخبراته السابقة.

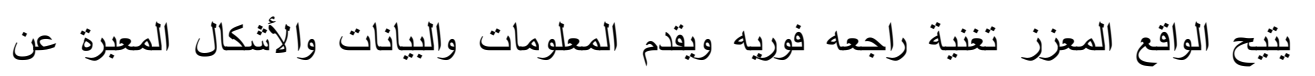
الصورة التي يشاهدها المتعلم. تتبع تقنية الواقع شخف وحب المتحلمين لاستخدام الهواتف الذكية والأيباد ويساعد على جنب

$$
\begin{aligned}
& \text { انتباههم (نرمين مصطفى:Y V V ) . } \\
& \text { طرق الواقع المعزز }
\end{aligned}
$$

أولاً: اعتمادا على صورة ثابتة (بوجود علامة)

يسمى هذا النوع (Marker based-AR)؛ حيث يعتمد بشكل أساسي على التعرف صورة

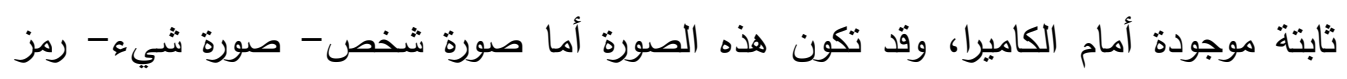
أو غير ذلك. يحدد الجهاز إحداثيات هذه الصورة واتجاهها ثم يقوم بإظهار عناصر (QR) الواقع الافتراضي سواء الفيديو أو العناصر ثلاثية الأبعاد بالاعتماد عليها كما هو موضح

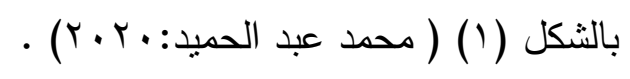




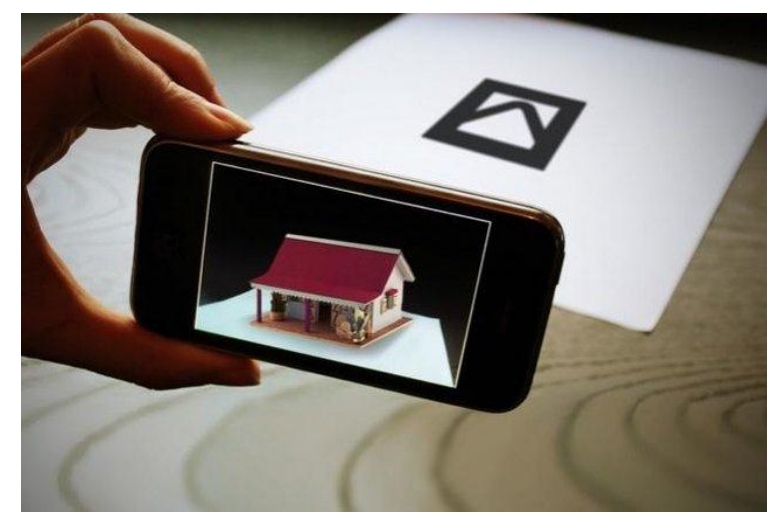

شكل رقم (1) الواقع المعزز اعتمادا على صورة ثابتة (بوجود علامة) :2019 Yannis Zavoleas

ثانيا: الموقع (باون وجود علامة Marker-less AR)

هو عبارة عن طريقة ينم توظيفها لتحديد المواقع بالارتباط مع برمجيات أخرى؛ منها: تحديد المواقع (GPS)؛ وتكنولوجيا التتلت (Triangulation Technology) التي تقوم مقام الدليل في توجيه المركبة أوالسفينة أو الفرد إلى النقطة المطلوب الوصول إليها باستخدام نقاط التقاء فرضية وتطبيقها على الواقع؛ ويتضح ذللك في حال استخدام الهواتف الذكية المدعومة ببرمجة تحديد المواقع (GPS) التي تساعد على تحديد مكان الفرد. ومن خلال مجموعة من الأسهم والإثارات الفرضية والواقعة على صورة حية تقوم بتوجيه الفرد للوصول إلى النقطة الثانية المرغوب في الوصول إليها وعادة ما توجد هذه التقنبة في أجهزة الهواتف الذكية؛ والسيارات الحديثة؛ والمركبات المحددة الاستخدام كالمركبات العسكرية؛ وهي تتيح للسائق تحديد وجته وترشده إلى الطرق الواجب سلوكها للوصول إلى النقطة المطلوبة. وحتى اليوم ما زالت الثركات البرمجية تحاول التطوير في هذا النوع من الواقع المعزز لخدمة الأهداف العسكرية؛ بحيث تسنطيع تحديد النقاط المستهدفة لاى الدولة؛ أو حتى تحدد موقع قمر صناعي في

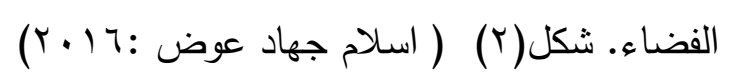




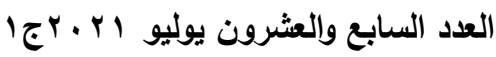

\section{المجلة العلمية لكلية التربية النوعية}

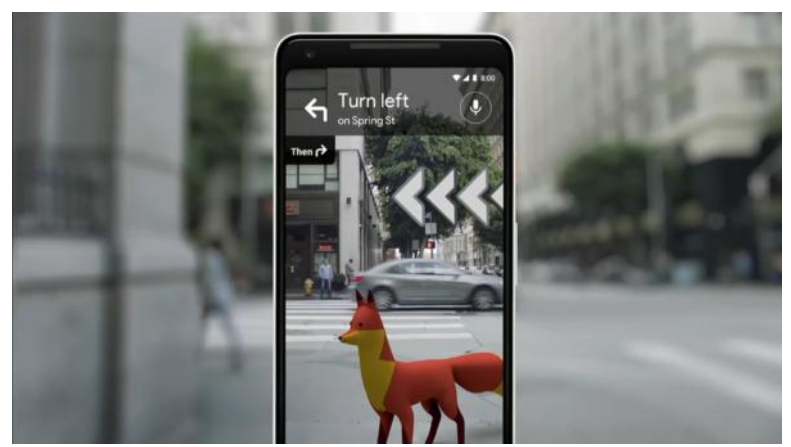

شكل رقم (r) الواقع المعزز اعتمادا على لموقع

https://www.business2community.com

Projection AR ثالثا: الإسقاط

هو أكثر أنواع الواقع المعزز شيوعا؛ ويعتمد على استخدام الصور الاصطتاعيةّ كإسقاطها

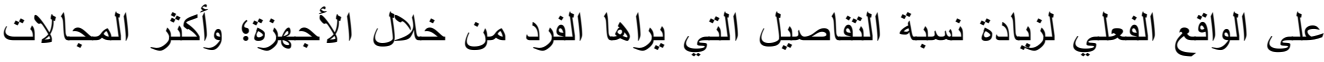
استخداما لهذا النوع من الواقع هو في مجالات بث المباريات الرياضية بحيث تنبع حركة

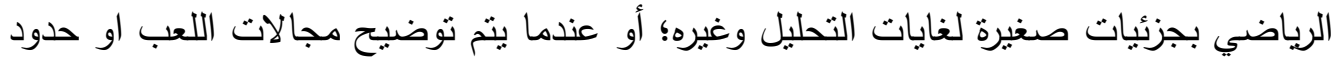

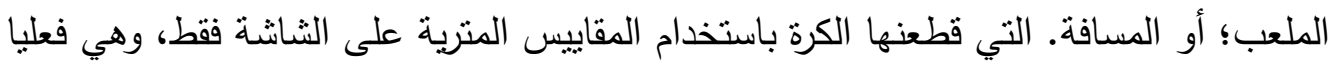

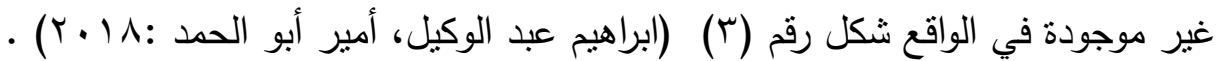

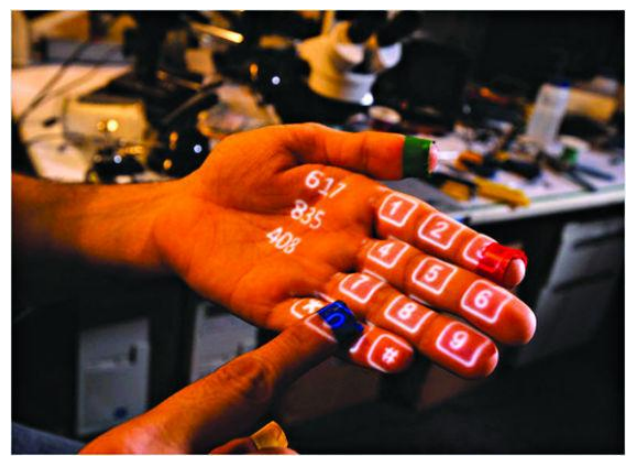

شكل رقم (r) الواقع المعزز اعتمادا الإسقاط

:2019 Yannis Zavoleas 


\section{رابعاً: التراكب Superimposition - based AR}

يسمى هذا النوع (Superimposition - based AR)؛ يعتمد مفهوم الواقع المعزز المعتمد على التراكب بإجراء عملية استبدال كلي أو جزي لعنصر موجود مسبقًا أمام الكاميرا بالمشهد الرقمي فيتم الاستبدال او الإضافة العلوية على المشهد بهدف الحصول على مشهد جديد ومعزز ببعض البيانات الجديدة؛ وأبرز مثال على ذه الطربقة هي تطبيق أيكيا الذي يسمح باستبدال الكتالوج الخاص به بقطع أثناث منزلي افتراضية ثلاثية الابعاد وغيرها من التطبيقات الطبية وتطبيقات الصيانة للأجزاء الميكانيكية المعقدة كما هو موضح بالثكل(ع)( محمد عبد

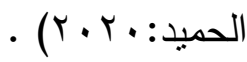

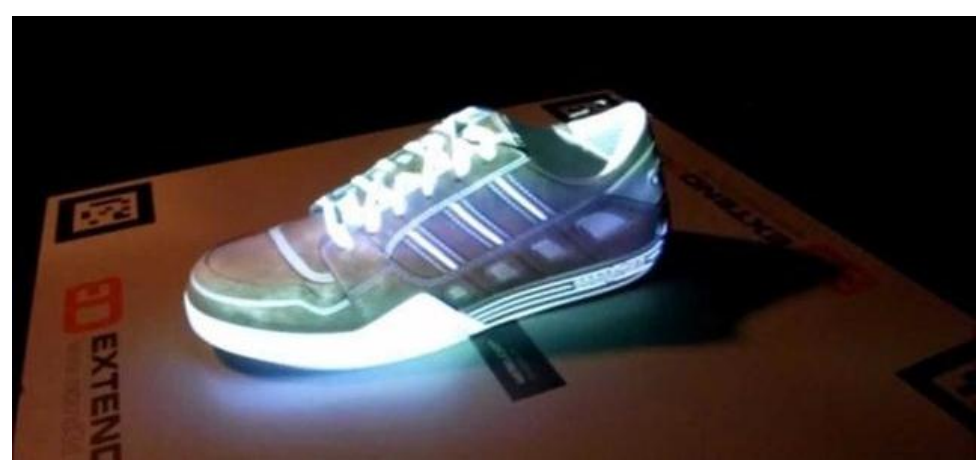

شكل رقم (ع) الواقع المعزز اعتمادا على التراكب

:2019 Yannis Zavoleas

خامسا: التعرف على الشكل recognition:

يقوم هذا النوع من أنواع الواقع المعزز على مبدأ التعرف على الثكل من خلال التعرف على الزوايا والحدود والانحناءات الخاصة بشكل محدد كالوجه أو الجسم؛ لتوفير معلومات افتراضية إضافية إلى الجسم الموجود أمامه في الواقع الحقيقي؛ وعادة ما يستخدم هذا النوع من بن الواقع ضمن المؤسسات الحكومية ذات المستوى عالي السرية من العمل كالمخابرات المركزية؛ أو أجهزة الاستخبارات؛ للتعرف على الوجوه والأشكال الجسمية للشثخاص والبحث عن ملفاتهم؛

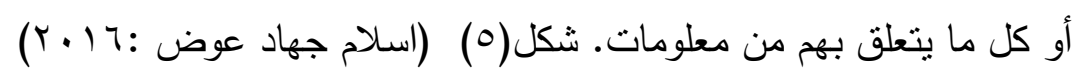




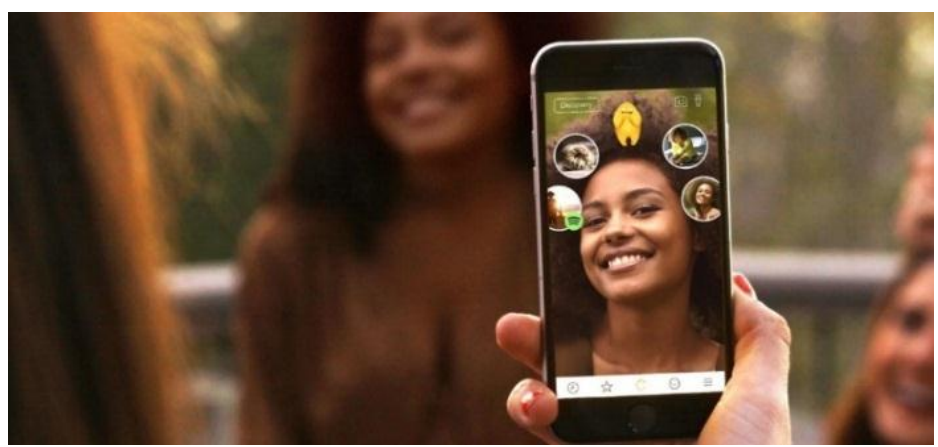

شكل رقم (0) الواقع المعزز اعتمادا على الثكل https://ssvar.ch

استخدام الواقع المعزز في التعليم

عرف مفهوم التعلم المعزز بأنه تقنية تعلم عند المتعلم؛ حيث تتبنى بيئات التعلم أساليبها بناء على احتياجات المتعلمين في هذا السياق على بيئات التعلم المادية كالصفوف الدراسية؛ بل قد يثير إلى بيئات التعلم الرقمية حيث يستطيع المتعلمون من خلالها تحفيز قدرتهم على الاكتشاف وهذا ما سيسهم بنهاية المطاف إلى اكتشاب قدر أكبر من المعرفة. وعادة ما ترتبط التقنيات المستخدمة في التعلم المعزز ارتباطاً وثيقاً بشاشات اللمس وثقنيات التعرف على مهى الصوت وهذا كفيل بأن يجعل سياقات التعلم متلائمة مع احتياجات المتعلم عن طريق عرض نصوص وصور واضحة إضافة إلى مقاطع فيديو أو مقاطع صوتية أو مجسمات ثلاثية الأبعاد

$$
\begin{aligned}
& \text { (خالا طلعت، مصطفى أمين أمين:A (Y) } \\
& \text { تطبيقات الواقع المعزز في التعليم: }
\end{aligned}
$$

تم استخدام تقنية الواقع المعزز في العديد من مجالات التعليم المختلفة نذكر منها على سبيل المثال لا الحصر • التعليم من خلال إضافة الرسومات، الفيديوهات و الصوتيات إلى الكتاب المدرسي. • التعرف على المعالم السياحية المختلفة و المعلومات الخاصة بها عند رؤيتها بشكل مباشر إنه بدلاً من قراءة هذه المعلومات عبر الكتب. • فهم الكيمياء بشكل أفضل من خلال رؤية الجُزيئات و الذرات و عمليات الاندماج و التفكك التي تحدث بينهم بسهولة تامة. 
الكتب المعززة التي تتوافق مع نطبيقات خاصة بإضافة معلومات معززة.

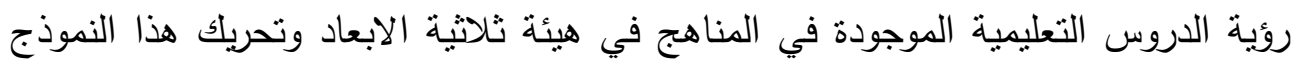
ثناثي الابعاد عن طريق تحريك الكتاب امام كاميرا الأجهزة المحمولة. (مصطفى أمين الإدئ

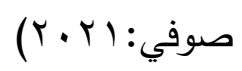

\section{التطبيقات والبرامج التي استخدمت فيها هذه التقنية في التعليم:}

خأ Elements 4D : منتج يستخدم تقنية الواقع المعزز؛ يمكن من خلاله خلق افتراضية من خلا الأجهزة الذكية. هnatomy 4D تطبيق يمكن للمتعلم من خلاله تتريح الجسم البشري واستكثاف أجزتّه

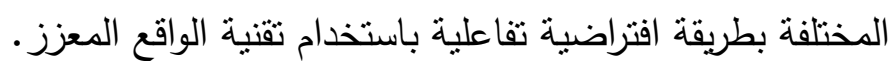

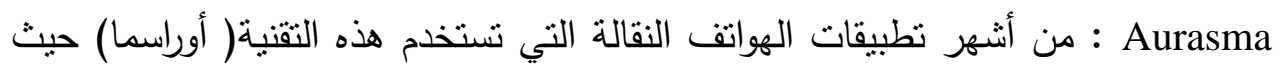

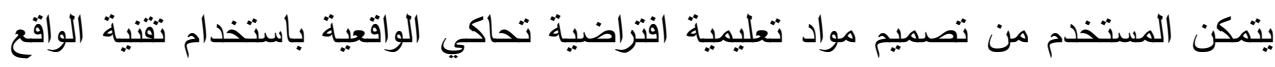

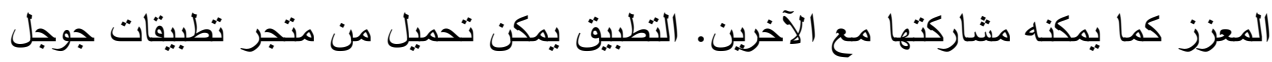

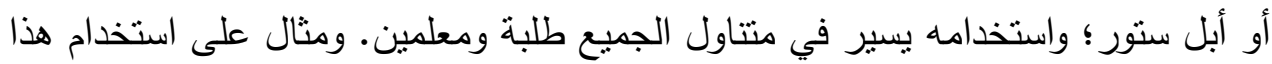

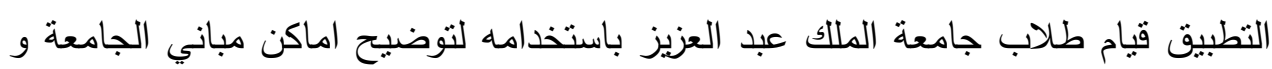

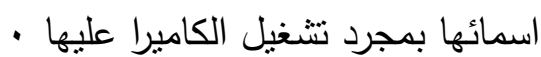
" Layar

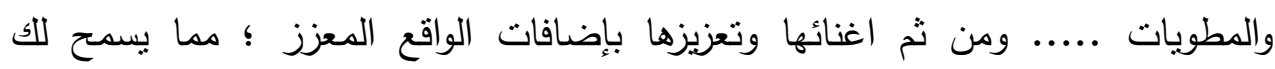

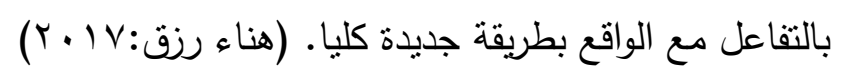
ثانيا: تصميم الأزياء الرقمي يتتاول هذا المحور تصميم الأزياء الرقمي من حيث تعريفة ، نشأته ،أهميته تعريف تصميم الأزياء الرقمي

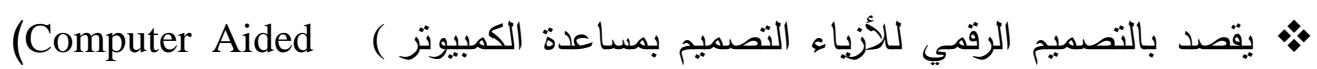
(Design

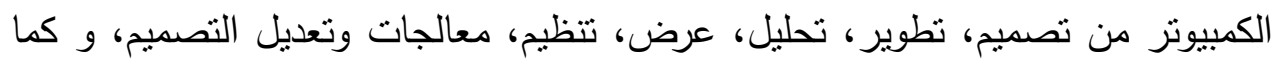

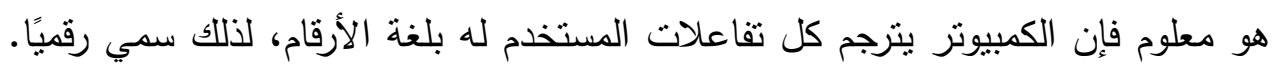


وفي الآونة الأخيرة تم الاتجاه إلى إتمام عملية التصميم باستخدام برامج التصميم الرقمي

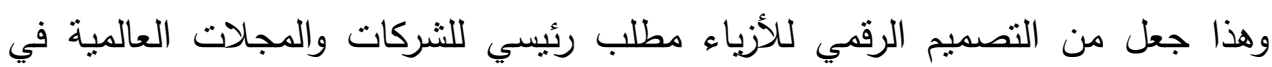

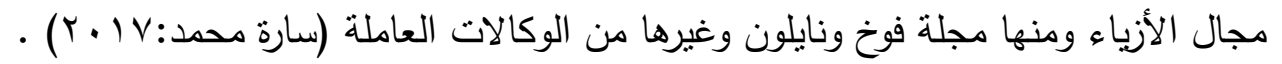
نشأة التصميم الرقمي للأزياء

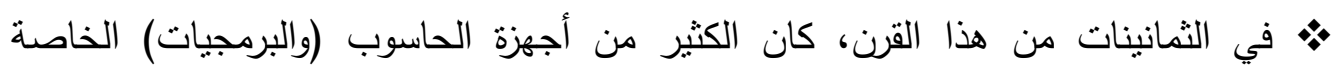

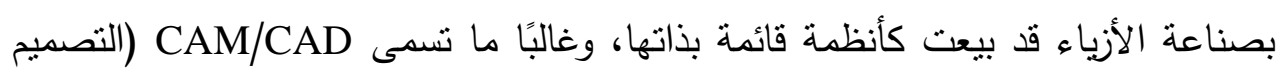

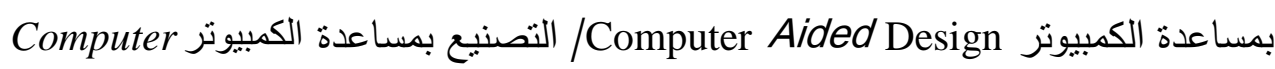
‘(Aided Manufacturing وهذا لا يمكن فقط أن بنظم ويسرع عملية التصميم ولكن بمكن أيضًا أن بصنع قطعة آلية

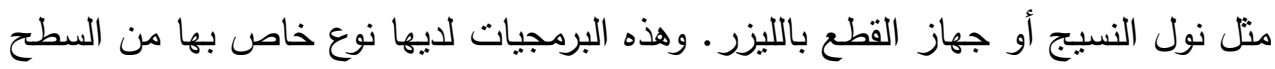

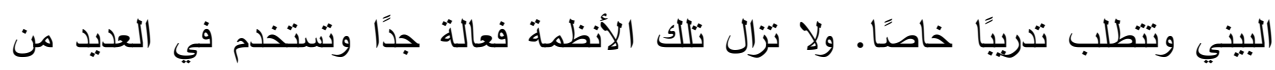

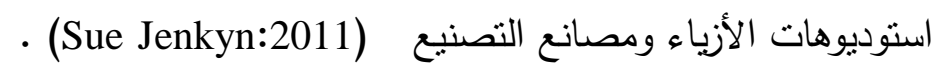

ومنذ ظهور وسائط الجرافيك الرقمية لأول مرة في الثمانينات تبعها ظهور المواسح

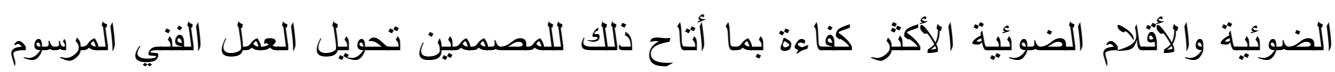

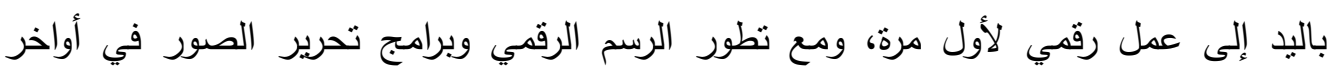

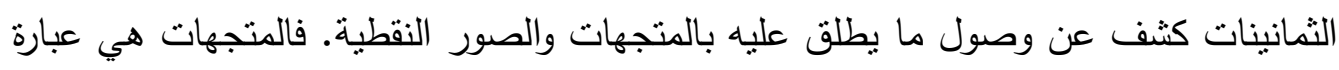

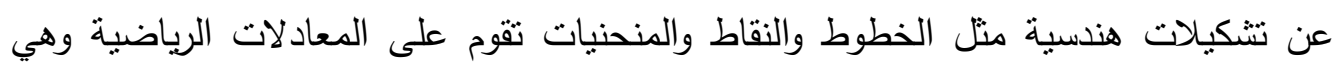
تتتج خطوط واضحة تكون مناسبة للرسم المسطح للملابس أو المواصفات الفنية ومايميزها أن ولن ولني

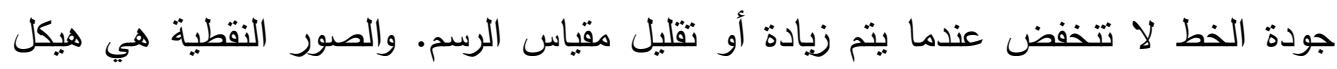

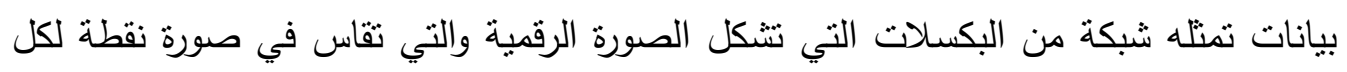

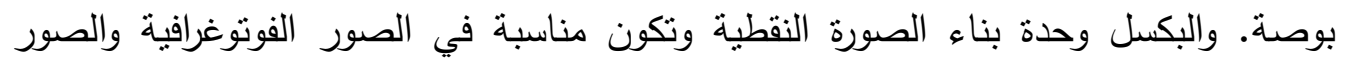

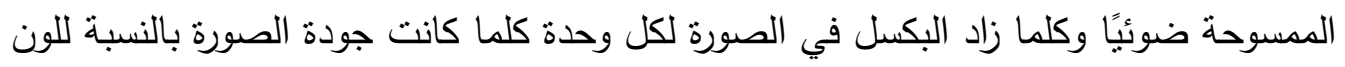
ودرجة الوضوح أفضل. ومنذ أول استخدام لها جعلت برامج الجرافيك تتطور تطورًا كبيرًا ومستمرًا وتوسعت إلى مجموعة متتوعة من واجهات المستخدم المنطورة التي يمكن استخدامها

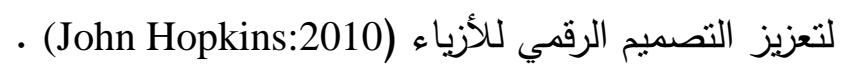


واليوم أصبح استخدام مصمم الأزياء للكبيوتر مطلب أساسي لمواكبة تحديات الأسواق ،

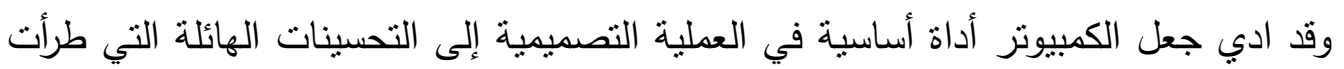
على الكميات، وسهولة الاستخدام وسعر أنظمة الكمبيوتر والبرمجيات لقطاع الأزياء إلى تغيير تدريجي في العلاقة بين مصممي الأزياء وأجهزة الكمبيوتر • ولم يقف الأمر علي ذلك بل نبئ نشاء

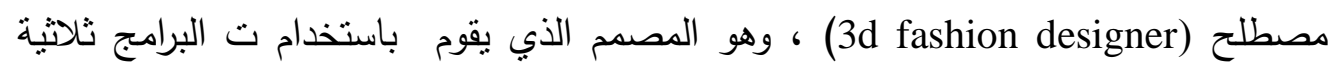

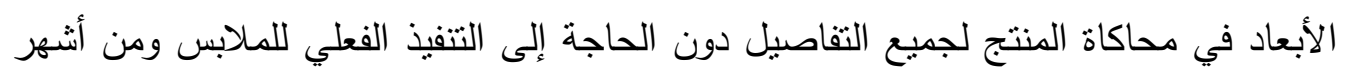

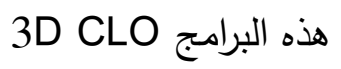
أهمية استخدام التصميم الرقمي للأزياء

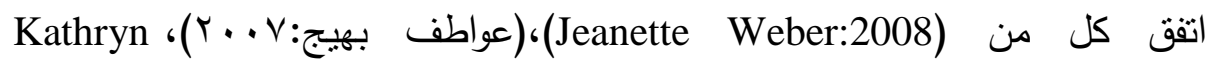
:2012) John Hopkins،( Jaeil Lee:2010)،(McKelvey- Janine Munslow:2003)

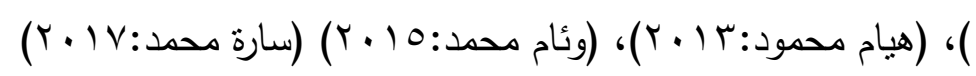
- الحصول على أنواع مختلفة من مفردات الزي مثل الأكوال والياقات بسرعة وسهولة.

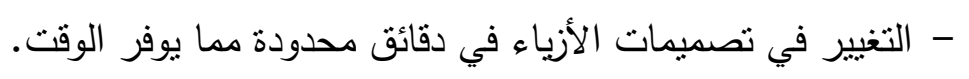
- رؤية التصور النهائي للتصميم بالثكل الواقعي مما يقلل التكلفة.

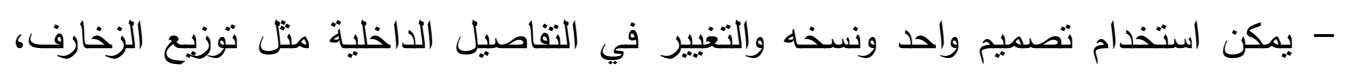
القصات، الأقشة، وأطوال التصميم للحصول على واهي عدد لا نهائي من التصميمات. - وإضافة التصميمات الطباعية والمنسوجة والصور الرقمية للمنتج الملبسي.

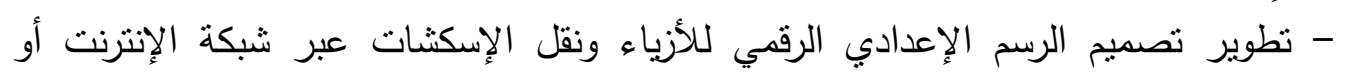
بالبريد الإلكتروني.

- إمكانية تحريك الأشكال المجسمة وتدويرها في شتى الاتجاهات لاختيار أفضل الحلول. - إمكانية الحصول على التصميم الواحد للموديل بعدة ألوان وخامات وأحجام واتجاهات. - إمكانية تسويق المنتج الملبسي بشكل يجذب العميل من خلال تحويل التصميم ثنائي الأبعاد

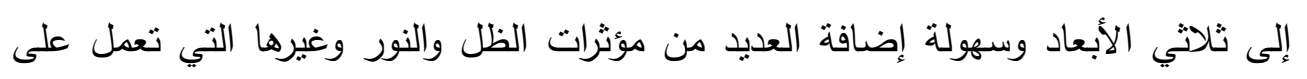
عرض التصميم بشكل يجذب العميل.

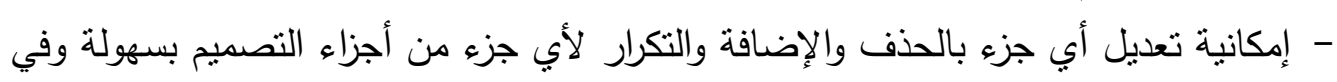
وقت قليل مما يتيح سرعة الحلول الابتكارية لمصم الأزياء و الاستجابة السريعة لمنطلبات الأسواق. 
- الدقة الفائقة في تتفيذ التصميم الملبسي الأمر الذي يتطلب العديد من الوقت والجهد بالطريق التقليدية ويصعب في بعض الأحيان الحصول عليه بالطريقة النقليدية.

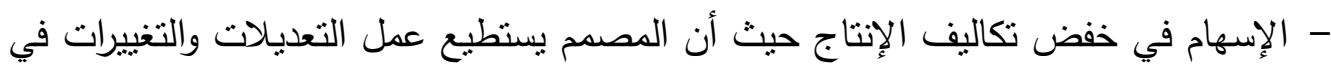

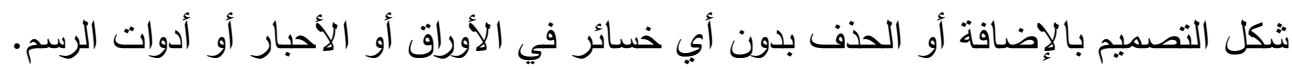

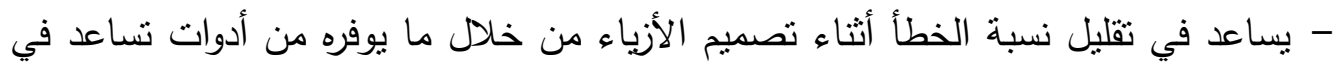
التعديل و إمكانية التراجع عن خطوة أو أكثر أثناء التصميه.

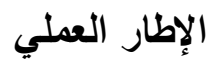

ا ـ خطوات إعداد التطبيق المقترح - قامت الدارسة بإعداد تطبيق لتتمية مهارة تصميم الأزياء باستخدام تقنية الواقع المعزز في

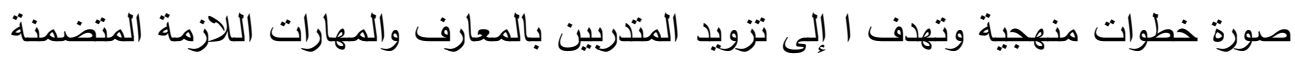
بداخلها في صورة خطوات منهجية أعدت مسبقًا كالآتي:

r r. موضوع التطبيق المقترح

- - هو تطبيق مقترح علي أجززة المحمول بهدف انشاء محتوي لمقرر تصميم الأزياء لتتمية

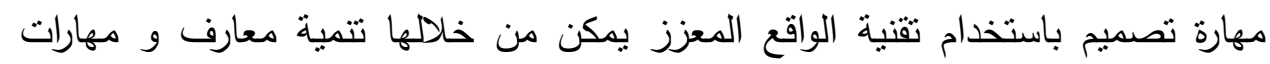
المتدربين لرفع وتتمية مسنواهم المهاري في تصميم الأزياء الرقمي مما يؤدي إلى خروج

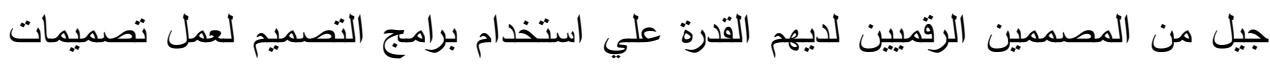

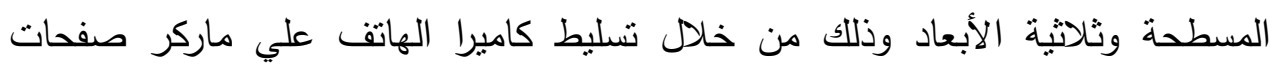

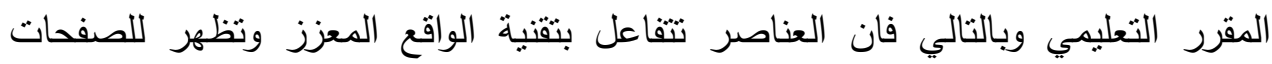

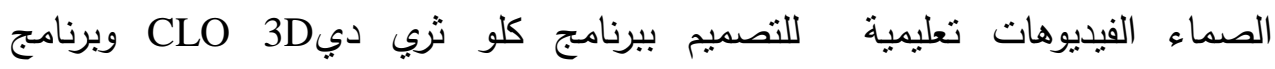

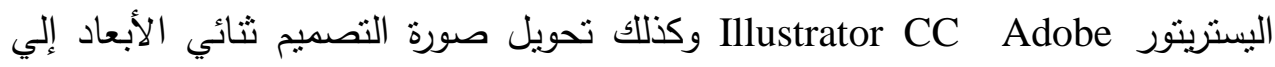
ثلاثي الأبعاد لتفاعل الدارسين معه وتحويل الصور ثنائية إلى أصوات للتعريف بأجزاء القطعة المراد تصميمها. 


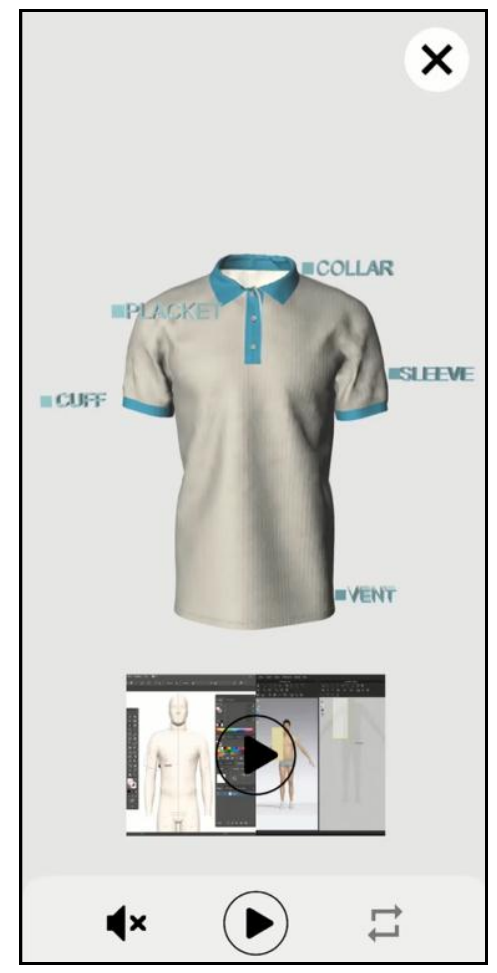

شكل(6) يوضح مثال من النطبيق المقترح

r. الأهداف العامة للمنظومة

- - تمية القدرات المعرفية، والمهارية، والاتجاهات لدى مصمدي الأزياء الرقميين ليكون لديهم

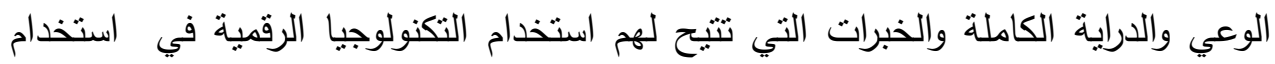

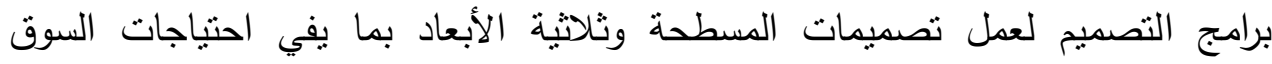

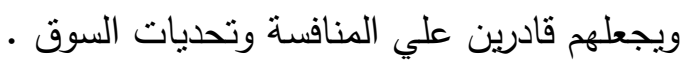

نتائج الارسة ومناقشتها صدق وثبات أدوات الدراسة بطاقة الملاحظة وئبات أدوات • مثائج صدق الاتساق الداخلي. للتحقق من صدق الاتساق الداخلي لبطاقة الملاحظة قامت الباحثة بحساب معامل

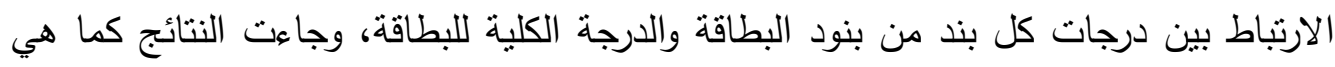

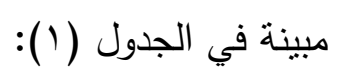


جدول ( ) : يوضح معاملات الارتباط بين درجات كل بند من بنود بطاقة الملاحظة والدرجة الكلية للبطاقة.

\begin{tabular}{|c|c|c|c|}
\hline الدلالة الاحصائية & مستوى الدلالة & معامل الارتباط & رقم البند \\
\hline دال & $\cdot . \cdot 1$ &.$\wedge V$ & 1 \\
\hline دال & $\cdots 1$ &.$V \varepsilon$ & $r$ \\
\hline دال & $\cdots 1$ & $.0 \mathrm{~V}$ & $r$ \\
\hline دال & $\ldots 1$ & $.0 \mathrm{~V}$ & $\varepsilon$ \\
\hline دال & $\cdots 1$ &..$\leqslant 9$ & 0 \\
\hline دال & $\cdots \cdot 1$ &.$v r$ & 7 \\
\hline دال & $\cdots 1$ & . & V \\
\hline دال & $\ldots 1$ & $\cdot . \leqslant \Lambda$ & $\wedge$ \\
\hline دال & $\ldots+1 V$ &..$\leqslant r$ & 9 \\
\hline دال & $\cdots \cdot 1$ & .04 & 1. \\
\hline دال &. $.1 r$ &..$\leqslant 0$ & 11 \\
\hline دال &. .1 & $. .7 \leq$ & ir \\
\hline دال &. .1 &.$\vee \vee 9$ & س \\
\hline دال &. .1 &.$\wedge \mathrm{V}$ & $1 \leq$ \\
\hline دال & $\cdots 1$ &. .00 & 10 \\
\hline دال & $\cdots 1$ &..$\leqslant 7$ & 17 \\
\hline دال & $\cdots 1$ & $.0 \%$ & iv \\
\hline دال &. $.1 r$ &..$\leqslant 0$ & 11 \\
\hline دال & $\cdots+1 r$ &..$\leqslant 0$ & 19 \\
\hline دال & $\cdots+1$ &.$V r$ & $r$. \\
\hline
\end{tabular}

يبين الجدول ( ( ) معاملات الارتباط بين بين درجات كل بند من بنود البطاقة والدرجة

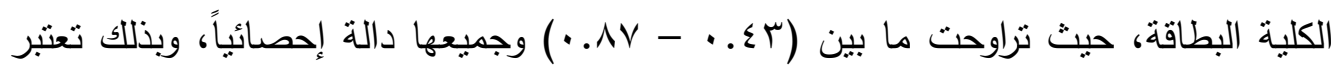
بنود البطاقة صادقه لما وضعت لقياسه.

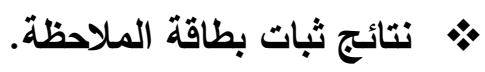
للتحقق من ثبات الملاحظة استخدمت الباحثة طريقة معامل ألفا كرونباخ وجاءت

$$
\text { النتائج كما هي مبينة في الجدول (Y). }
$$


جدول (r): يوضح نتائج اختبار ألفا كرونباخ للبطاقة.

\begin{tabular}{|c|c|c|}
\hline معامل ألفا كرونباخ & عدد العبارات & \\
\hline .991 & $r$. & مقياس الاتجاه \\
\hline
\end{tabular}

يبين الجدول (r) معامل الثبات لبطاقة الملاحظة، حيث بلغ (19.9. (9)، وهى نسبة

ثبات مرتفعة، مما يطمئن الباحثة لنتائج تطبيق المقياس.

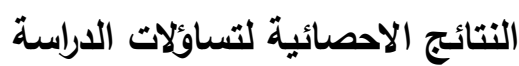

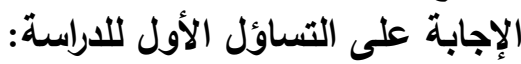

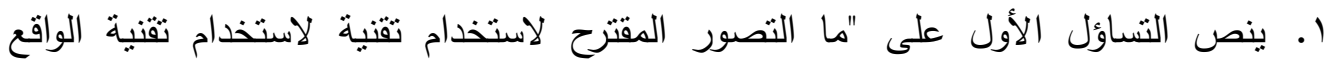

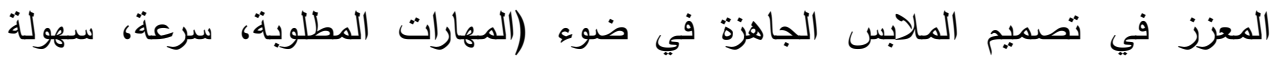
الاستخدام)".

تمت الإجابة علية من خلال عمل تطبيق رقمي يستخدم تقنية الواقع المعزز من خلال

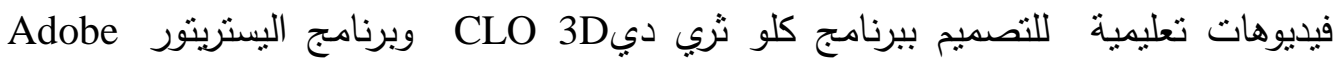
Illustrator CC الدارسين معه وتحويل الصور ثنائية إلى أصوات للتعريف بأجزاء القطعة المراد تصميمها.

\section{الإجابة على التساؤل الثاني للاراسة:}

ينص التساؤل الثاني على "ما فاعلية استخدم تقنية الواقع المعزز علي تتمية مهارة تصميم

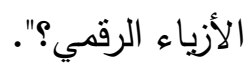

وللتحقق من صحة هذا الفرض استخدمت الباحثة اختبار "ت" للعينات المرتبطة، ومعادلة نسبة الفاعلية لماك جوجيان، وجاءت النتائج على النحو التالي:

جدول (ץ): دلالة الفروق بين منوسطي درجات مجموعة الدراسة فى التطبيقين القبلى والبعدي لاستخدام تقنية الواقع المعزز فى تصميم الملابس الجاهزة.

\begin{tabular}{|c|c|c|c|c|c|c|c|}
\hline \multirow{2}{*}{ نسبة } & \multirow{2}{*}{ العظدى } & \multicolumn{3}{|c|}{ اختبار "ت" } & \multirow{2}{*}{ المعياري } & \multirow{2}{*}{ المتوسط } & \multirow{2}{*}{ التطبيق } \\
\hline & & مستوى الدلالة & درجات الحرية & قيمة (ت) & & & \\
\hline \multirow{2}{*}{$\begin{array}{r}\cdot 11 \\
1\end{array}$} & \multirow{2}{*}{01} & \multirow{2}{*}{$\cdots \cdots$} & \multirow{2}{*}{ rq } & \multirow{2}{*}{ YV.OV } & $1 . r \wedge$ & $1 \wedge . \ldots$ & التطبيق القبلي \\
\hline & & & & & $7 . M$ & $\leqslant 0 \ldots$ & التطبيق البعدي \\
\hline
\end{tabular}

يبين الجدول (ץ) نتائج اختبار "ت" لدلالة الفروق بين متوسطي درجات مجموعة الدراسة

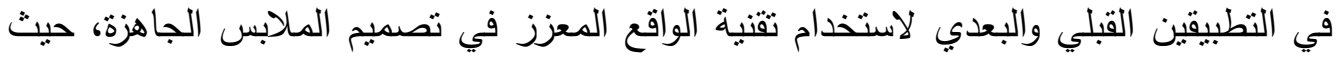




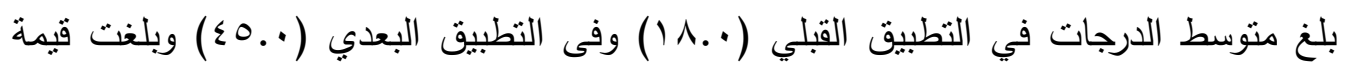

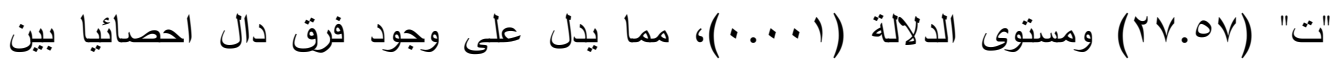

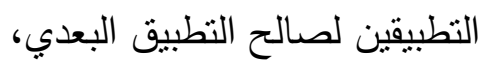

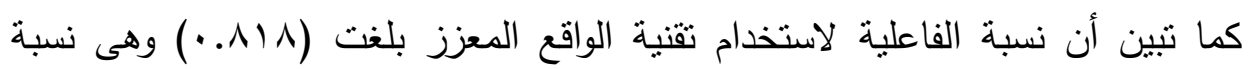
أكبر من (7 . ·) التي حددها ماك جوجيان للحكم على الفاعلية، مما يدل على فلى فاعلية استخدام تقنية الواقع المعزز في تصميم الملابس الجاهزة.

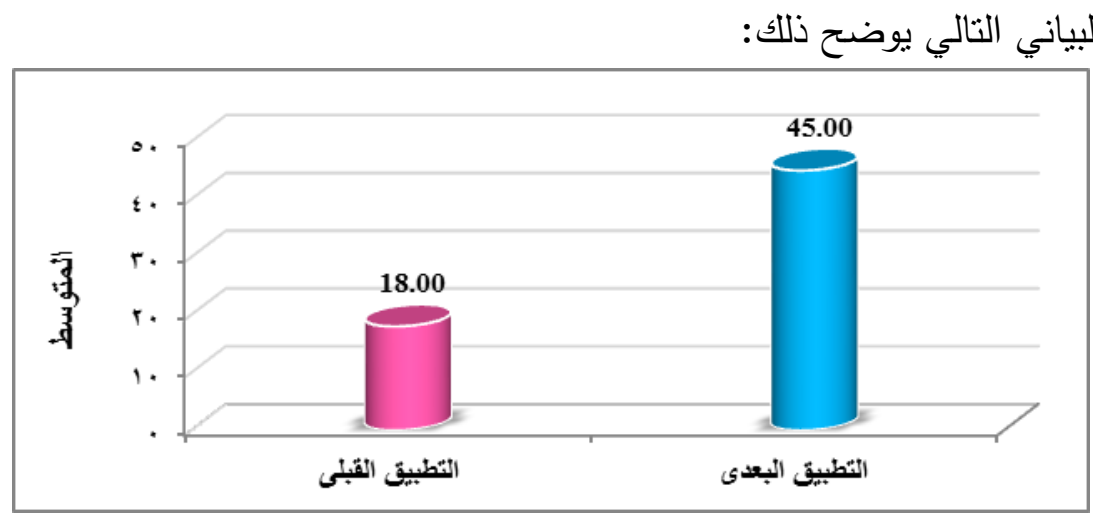

شكل (V): يوضح منوسطي درجات مجموعة الدراسة من عمال المصانع في التطبيقين القبلي والبعدي لاستخدام تقنية الواقع المعزز في تصميم الملابس الجاهزة.

من الجدول (r) ونتائجه والشكل البياني (V) تمت الاجابة على التساؤل الثاني للاراسة.

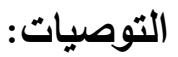
بناء على النتائج التي توصل إليها البحث تم التوصية بالاتي:: تفعيل التطبيق المقترح بمناهج تصميم الأزياء.

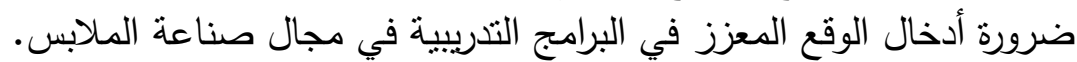

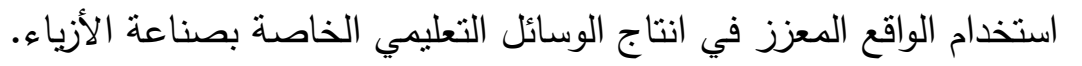

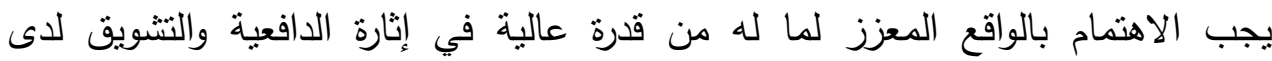

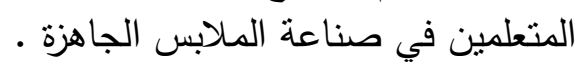
تجهيز الكليات والمعهز التعليية بقاعات وأجهزة وشاشات تمكن المعلم من استخدام تقنية

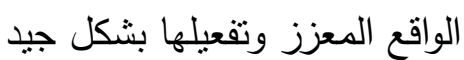
العمل علي أنشاء المحتوى التعليهي باستخدام تقنية لواقع المعزز لتفعيل التعلم الذاتي بفاعلية. 


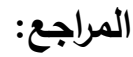

أولا: المراجع باللغة العربية:

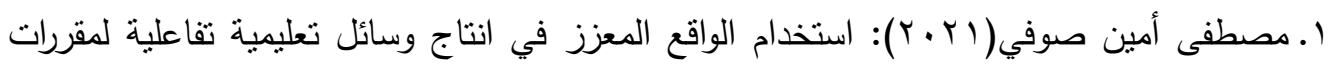

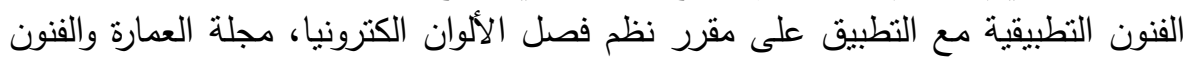

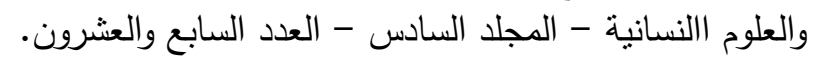

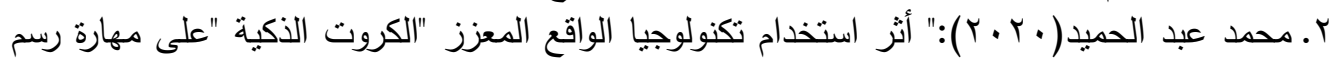

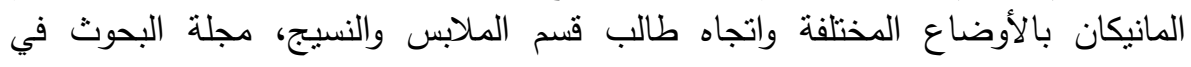

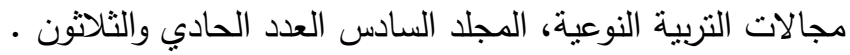

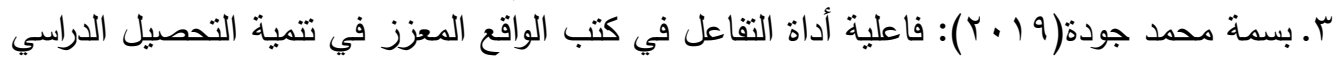

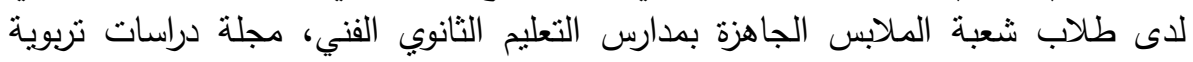

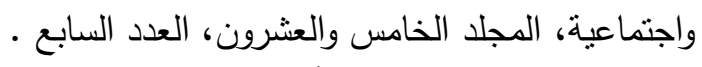

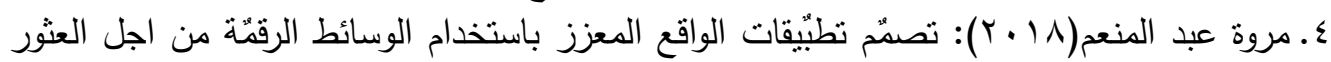

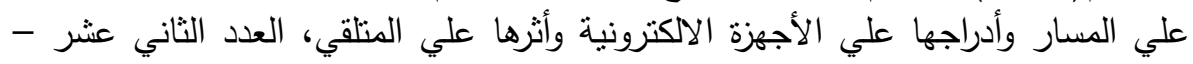
الجزء الثاني، مجلة العمارة والفنون.

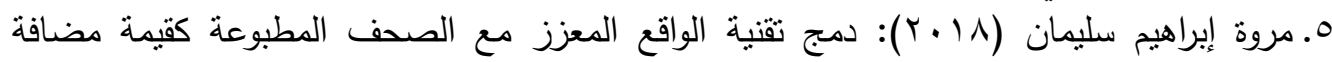

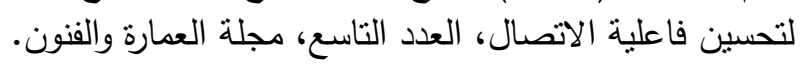

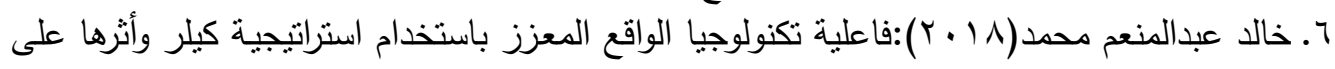

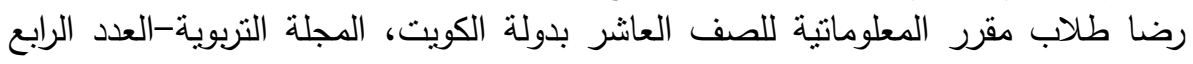

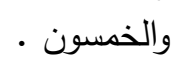

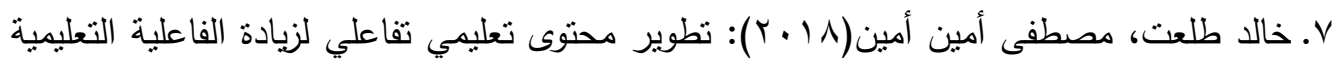

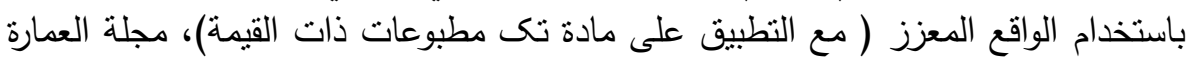

$$
\text { والفنون العدد الثاني عشر - الجزء الثئ الثناني. }
$$

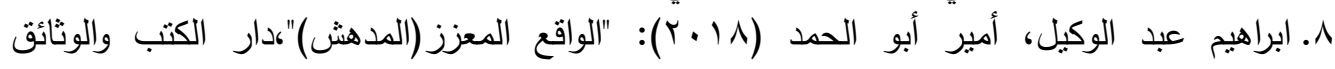

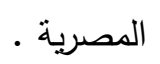

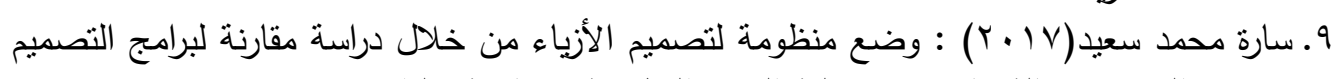

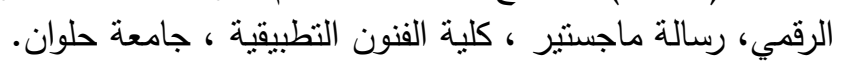

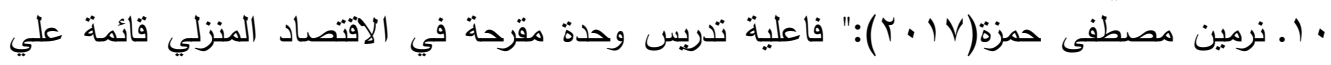

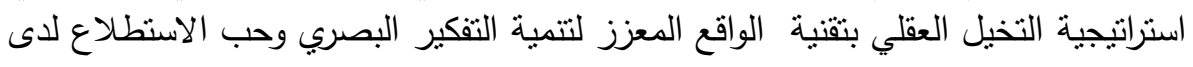

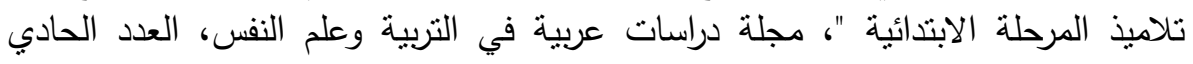

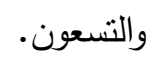

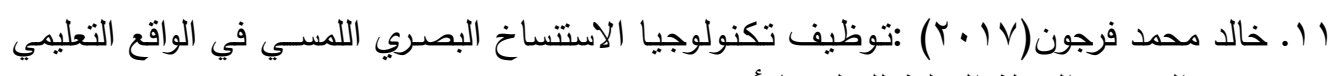
المعزز ، المجلة الدولية للتعليم بالأنترنت. 


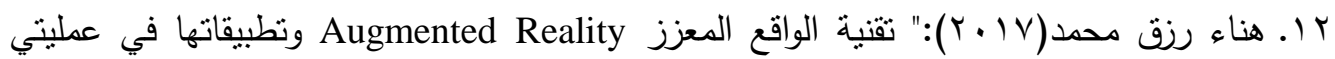

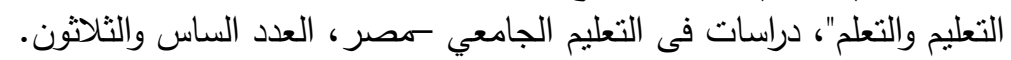

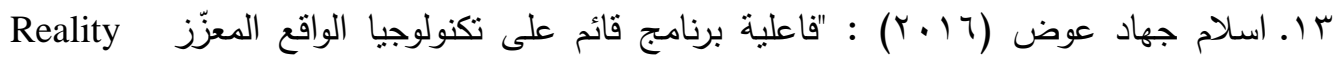

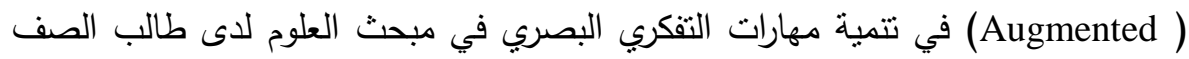

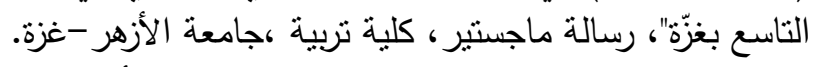

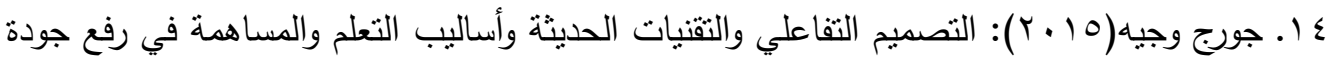

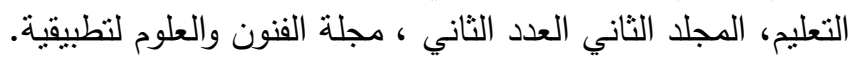

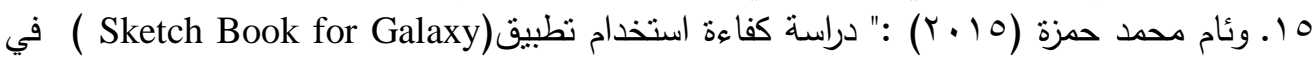

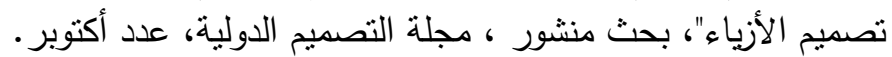

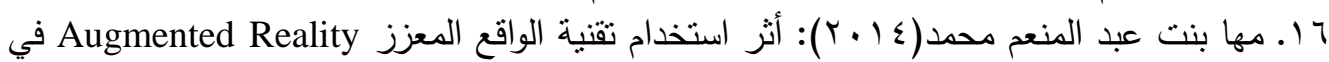

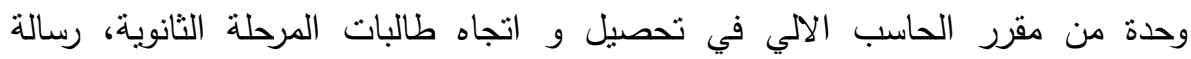
ماجسنير ، كلية التربية جامعة أم القرى.

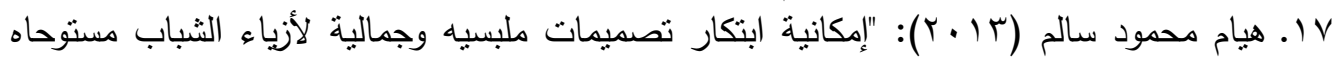

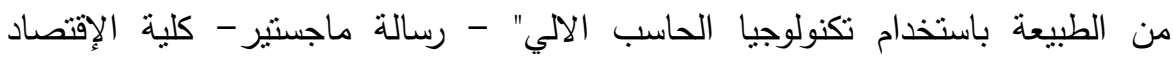

$$
\text { المنزلي - ملابس ونسيج- جامعة المنوفية. }
$$

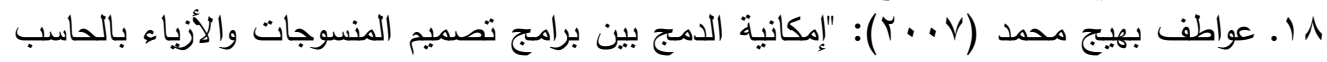

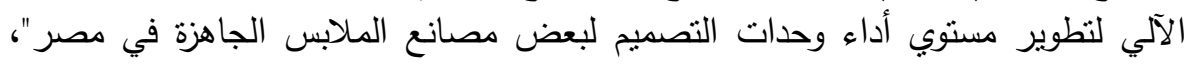

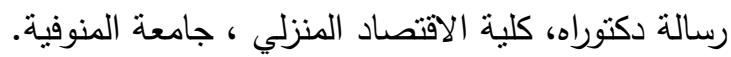

\section{ثانيا:المراجع الأجنبية}

19. Yannis Zavoleas (2019): PUTTING THE AR IN (AR)CHITECTURE: Integrating voice recognition and gesture control for Augmented Reality interaction to enhance design practice, Conference: Intelligent \& Informed - 24th CAADRIA Conference at: Victoria University of Wellington.

20.John Hopkins(2012):" Fashion Design: The Complete Guide", A\&C Black.

21.Sue Jenkyn (2011): "Fashion Design (Portfolio)", Laurence King; 3 edition.

22.John Hopkins(2010): "Basics Fashion Design 05: Fashion Drawing" ,Ava Publishing AS.

23.Jaeil Lee (2010) :" Technical Sourcebook for Designers", Bloomsbury Academic USA.

24.Kathryn McKelvey, Janine Munslow(2003):"Fashion Design process, innovation , practice" ,Blackwell Science Ltd.

ثُالثا: مواقع الإنترنت

25.https://www.business2community.com

26.https://ssvar.ch/blippar-brings-facial-recognition-ar-profiles-to-mobile-app/ 